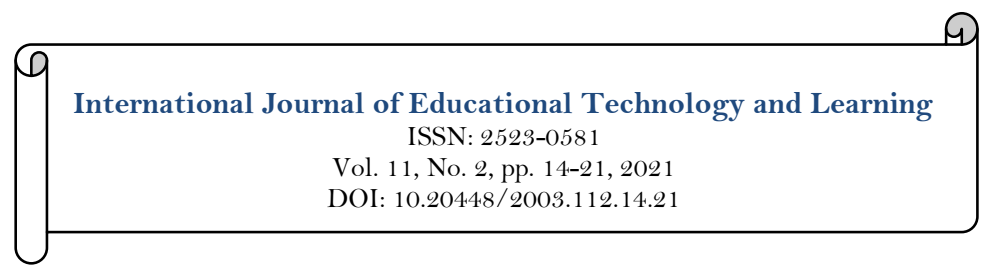

\title{
Non-English Major Students 'Motivation in English Classrooms: Evidence from a University Setting
}

\section{Nguyen Huynh Trang}

School of Foreign Languages, University of Economics Ho Chi Minh City, Vietnam. Email:trangnh@ueh.edu.vn

\begin{tabular}{|c|c|}
\hline Abstract & \\
\hline $\begin{array}{l}\text { In learning and teaching English as a foreign language, motivation is } \\
\text { crucial to success. The purpose of this study is to discover whether non- } \\
\text { English-majored students are motivated in learning English and to find out } \\
\text { what factors can help motivate them to learn English. The study mainly } \\
\text { employed a questionnaire which is developed and administered base on Khau } \\
\text { and Thach (2021)'s framework to collect the data. It was delivered to 54 } \\
\text { non-English-majored students who are at their third year of study at a } \\
\text { public university in Ho Chi Minh City, Vietnam. The results highlighted } \\
\text { various researches that have been conducted on the elements that influence } \\
\text { motivation. The data showed that the participants' motivation level is at } \\
\text { medium rank. It could be inferred that these participants were motivated to } \\
\text { learn English at university. The current study also found that students' } \\
\text { motivation was mainly affected by four factors which are teacher's } \\
\text { personality, teacher's methodology, facilities for studying and classmates. The } \\
\text { results of the study contribute to the field of motivation research in EFL } \\
\text { setting. }\end{array}$ & $\begin{array}{l}\text { Keywords: } \\
\text { Motivation } \\
\text { Factors } \\
\text { Non-English major students } \\
\text { University. } \\
\text { Licensed: } \\
\text { This work is licensed under a } \\
\text { Creative Commons Attribution } 4.0 \\
\text { License. } \\
\text { Publisher: } \\
\text { Scientific Publishing Institute } \\
\text { Received: } 16 \text { November } 2021 \\
\text { Revised: } 20 \text { December } 2021 \\
\text { Accepted: } 24 \text { December } 2021 \\
\text { Published: } 31 \text { December } 2021\end{array}$ \\
\hline
\end{tabular}

Funding: This study received no specific financial support.

Competing Interests: The author declares that there are no conflicts of interests regarding the publication of this paper.

\section{Introduction}

Motivation is vital aspect in the Foreign Language Learning process because it provides the initial push for a successful language learning process to get started. In the classroom context, the teacher must provide motivational activities or tactics to keep the students' attention and maintain it throughout the class. Once students are motivated, they will pick up language quickly.

According to Ebata (2008) develops successful second language (L2) communicators by instilling confidence in them. Furthermore, it has the potential to encourage learners to continue learning even after achieving a specific goal. Another reason some scholars are interested in motivation research is its complexity as well as the fact that motivation appears to be linked to a multitude of elements, each of which can be studied separately.

This research aims to examine a group of non-English majors' motivation when taking English as a Foreign Language (EFL) courses. The study is guided by two research questions: (1) Are the non-English majored students motivated to learn English at university? (2) What are the factors influencing non-English major students' motivation to learning English? 


\section{Literature Review}

\subsection{Definition of Motivation}

Gardner (1985) defined motivation as "Attitudes toward the teacher, students, coursework, curriculumrelated activities, and all other elements of the state in which a language is taught,". Attitudes about the learning situation have an impact on overall motivation to learn a language. According to this hypothesis, a motivated individual has the potential to learn a foreign language, a desire to learn a language, and thus can be motivated to learn a language in the long run. Motivation or demotivation has long been recognized by researchers as one of the most significant aspects of second language learning (Seda \& Zahitjan, 2016). The attempt and desire to learn a language, as well as favorable attitudes toward learning it, are referred to as motivation in second language acquisition (SLA) (Dörnyei, 1994).

\subsection{Type of Motivations \\ 2.2.1. Intrinsic and Extrinsic Motivation}

Over the years, a considerable deal of research has been done on the subject of motivation. There are two primary types of motivation, according to Brown (2000) and Gardner (1985): integrative and instrumental. Falk (1978) in his book Linguistics and Language: A survey of basic concepts and implications, believes that students who like the people who speak the language, admire the culture, and want to become familiar with or even integrate into the society in which the language is used are the most successful when learning a target language.

\subsection{Instrumental and Integrative Motivation}

As a result, it is critical to recognize that motivation is a complex term. In fact, psychologists distinguish between two types of motivation: extrinsic and intrinsic motivation. They were coined by Dörnyei (as cited by Gilakjani, Leong, and Sabouri (2012)). Intrinsic motivation refers to the desire to participate in an activity because it is enjoyable. Extrinsic motivation refers to actions taken in order to achieve a certain goal, such as receiving a reward or avoiding a punishment.

Brown (2000) identifies a link between the two types of motivation. If someone else wants the L2 learner to know the L2 for integrative purposes, extrinsic motivation may turn out to be integrative motivation; extrinsic motivation may turn out to be instrumental motivation if an external power wants the L2 learner to acquire the L2 language. Factors effect on motivation in SLA.

To fulfil the purpose of the study, the survey was seeking to answer the following research questions:

1. Are non-English majors motivated to study English at university?

2. What factors can contribute to non-English majors' motivation in studying?

\section{Related Studies}

Several factors influence students' motivation in foreign language learning, including sex, age, culture, personal interests, previous acts, expectations, social or effective aspects, environment, and so on (Noemi, 2014).

In teaching and studying English as a foreign language, Seda and Zahitjan (2016) looked into the importance of motivation and the elements that influence students' motivation. The effects of parental, environmental, and instructor attitudes were investigated. A total of 40 first-grade pupils from the English Language Teaching department took part in the study. A survey was presented to the participants, which contained numerous statements relating to the issues indicated. The findings revealed that learners were more motivated to learn English when their parents supported and encouraged them. Pupils were significantly more motivated when they worked with their peers, according to the study. Reinforcing learner beliefs also encouraged students. Furthermore, the findings of this study indicated a variety of motivational behaviors and tactics.

At first glance, Bernaus and Gardner (2008) looked at the role of motivation in foreign language learning as well as the elements that influence motivation. The study included 137 secondary school pupils. There were correlations between the student's English skill and motivation. The findings revealed that teachers had an impact on students' motivation and that motivation and foreign language learning have substantial relationships.

By the same token, to find out to what extent various factors affect these students' motivation and performance in Foreign Language Learning as well as to deal with some motivational strategies to promote these students' motivation. Noemi (2014) discovered a group of 20 students from an Intermediate Level Trade Course. The finding showed that having a good relationship with students is also essential to keep them motivated. As a result, during the teaching session, the teacher should have a pleasant mood and have a favorable interaction with the pupils, both academically and personally. In the classroom, students' motivation can be boosted by providing them with useful and realistic resources, active challenges, and a conducive learning environment.

Surprisingly, Khau and Thach (2021) did a study to see if English-majored students are motivated to learn English or not, and this paper focuses on extrinsic motivation variables to see what aspects can help them stay 
motivated in their English learning journey. A questionnaire was created and distributed to 52 Englishmajoring students in their third and fourth years of study to evaluate this hypothesis. After that, the quantitative method was employed in this study. The study's findings imply that learner motivation is linked to study facilities and the personality of the teacher, both of which might assist learners to think more positively and so be more motivated in their language learning process.

Tsai and Chang (2013) studied the inner motivation and anxiety of English learning as experienced by English as a Foreign Language (EFL) students across majors, genders, and language competence levels. A total of 857 freshmen from a technical institution in Taiwan were polled and analyzed for the study. English learning anxiety influenced English learning motivation in varied ways depending on gender and major, according to structural equation modeling studies. In general, instrumental rather than integrative motivation drove most of the students to learn English, and their levels of English language class anxiety were higher than their levels of English use and testing anxiety.

As part of a research project in Vietnamese contexts, Nguyen (2015) investigated methods to motivate non-English major education students to study English. A mixed -method design was employed to collect data. For the quantitative data, questionnaires were administered to 60 non-English majors in Hanoi Pedagogical University 2 and 60 other students in Hanoi University of Education. To collect qualitative data, five Vietnamese teachers and five English instructors were recruited to take part in the interviews. Three major findings emerged from this investigation. The first finding explored the fact that non-English students learn English mostly for professional prospects and worldwide communication. Teachers' behavior and teachers' support to students were the two most effective elements increasing students' motivation to study English. Internal variables generating demotivation, on the other hand, were found as a lack of goal setting and self-actualization.

In particular, Le (2012) did research to investigate learning motivation at the university level in order to determine whether motivation has an impact on students' English learning. A total of 290 students and seven English professors were invited to participate in the survey. The results showed that Students were both extrinsically and intrinsically motivated in the English subject, but their personal ways of studying and the heavy learning curriculum had an impact on their learning. Teachers' attitudes and perceptions of learning motivation are favorable, as they recognize the importance of motivation in developing students' English skills.

Shahla and Takkac (2021) conducted research to identify impediments and determine what factors motivate new immigrants to learn English. From June to December 2018, a cross-sectional quantitative study was undertaken at a polycultural center in Canada. This study had 325 people who registered and gave their consent. The findings revealed that the desire for career and economic advancement, as well as the desire to converse and identify with foreigners, are the primary motivators for new immigrants studying English as a second language.

From another perspective, the social, psychological, and cultural components of motivation in learning English as a second language in Kuwait are investigated in this study by Florentina, Cathy, and Iqbal (2020). Gardner's socio-educational model's perspectives are used to discuss the effects of motivation and learning experiences. A study of undergraduate students from a private university in Kuwait provided 233 completed questionnaires, which were used to compile the data. For descriptive data analysis, correlation analysis, t-tests, and ANOVA, the researchers used the SPSS application. On the basis of the data provided by the students' responses, descriptive statistics were generated. The findings demonstrated high levels of integrative and instrumental motivation, particularly among female students, which Hofstede's cultural aspects of certainty, femininity, and collectivism could explain. Significant levels were also recorded for English lessons and English use anxiety, which could be explained by Hofstede's power distance, which explains why teachers and teaching are held in such high regard.

In a communicative language learning context, Ochoa, Cabrera, Quiñónez, Castillo, and González (2016) wanted to discover more about the connection between communicative activities and students' enthusiasm to learn English as a Foreign Language (EFL). A questionnaire was completed by 180 senior high-school students and $8 \mathrm{EFL}$ teachers at a community in Ecuador's Amazon region. A face-to-face interview was conducted A mixed-method approach was used to assess the data collected, which included both quantitative and qualitative methodologies. Students and teachers both agree that communicative activities are inspiring, according to the findings. Furthermore, students are strongly encouraged to participate in communicative activities because they improve their fluency, pronunciation, and performance in the usage of English in a realistic and fun manner because students are confident when they assist one another during activity interaction.

Al-Ta (2018) conducted research on integrative and instrumental incentives for learning English as a university requirement. The participants in this study were 50 second-year undergraduate students studying English Communication Skills. The participants came from various majors so order to get a variety of perspectives on their drive to learn. Questionnaires were utilized to collect data by the researcher. The integrative and instrumental measures were modified from Gardner (1985) Attitude, Motivation Test Battery, and the questionnaire was divided into three portions. The study discovered that pupils are highly motivated 
to learn English in both integrative and instrumental contexts. Their instrumental motivation, however, is a little stronger than their integrative motivation. The researcher advises analyzing students' motivation in English language acquisition for speaking majors based on the findings of the study. He also recommends creating a classroom setting that encourages kids to study English and puts them in charge.

\section{Methods}

\subsection{Pedagogical Setting E Participants}

The participants of this study involved 54 non-English majors at a public university in Ho Chi Minh city, Vietnam. The convenience sample included 15 males (27.78\%) and 29 females (72.22\%). During their academic pursuit at the university, they have participated in four English classes, and they have studied with many lecturers with different teaching methods and diversified classmates. In addition, they have joined in various clubs at the institution that have assisted their studies as well as their soft skills.

\subsection{Research Instrument}

The data were collected by a questionnaire which was mainly adapted from the framework of Khau and Thach (2021). It comprised of two main sections: Part one included demographic questions. Part two contains 31 questions in total, which insisted the respondents to rate on a five-point Likert scale. Part 2 - cluster 1 consists of eight items aiming to address the answers for research question 1 "Are the non-English majored students motivated to learn English at university?". Part 2-cluster 2 includes 23 items which are divided into four factors answering the second research question "What are the factors influencing non-English major students' motivation to learning English?”.

\subsection{Research Procedure}

The data collection procedure includes three stages. The first stage is designing and evaluating the instrument. The questionnaire was mainly adapted from the framework of Khau and Thach (2021). The survey was piloted on 10 students as a sample to help the researcher validate the instrument. The questionnaire was carefully checked and edited before delivering to the participants. The second stage is delivering the questionnaire and collecting the responses. The questionnaire was conducted with the assistance of two teachers of English in the School of Foreign Languages in about fifteen minutes during break time. The last stage is analyzing the data which is carried out after the data collection. All the figures were subjected by software SPSS version 22.0. First, a scale test was run to check the reliability of the questionnaire as presented in Table 1 below. It reveals that the questionnaire was good enough to be delivered to the participants $(\alpha=.932)$. Then, descriptive statistic tests were run for each motivation factor to have general view of the most and least influential motivational factors presented in the next section.

Table-1. Reliability Statistics.

\begin{tabular}{c|c}
\hline Cronbach's Alpha & N of Items \\
\hline 0.932 & 31 \\
\hline
\end{tabular}

\section{Findings}

\subsection{The Questionnaire}

To assess the internal reliability coefficient, the questionnaire was processed and analyzed using SPSS software. The motivation of third and fourth-year English majors was divided into two components in this series of questions. The obtained data indicated that the questionnaire employed in this study was practical, with a Cronbach Alpha of .932 for a total of 30 items.

\subsection{Non-English Major Students' Motivation in Learning English}

Table 2 presents the mean scores of eight items related to motivation of non-English major students to learning English.

Table-2. Descriptive data on motivation questions.

\begin{tabular}{l|l|c|c}
\hline No & Items & Mean & S.D \\
\hline 1 & I really adore English. & 3.98 & 0.65 \\
\hline 2 & I like taking English classes. & 3.76 & 0.55 \\
\hline 3 & I like communicating in English with other people. & 3.56 & 0.56 \\
\hline 4 & I learn English to read English materials. & 3.87 & 0.61 \\
\hline 5 & I learn English to be more educated & 4.11 & 0.65 \\
\hline 6 & I learn English for my future job. & 4.08 & 0.58 \\
\hline 7 & I'm motivated in English classes. & 3.88 & 0.59 \\
\hline 8 & I learn English to know culture of its speakers & 4.02 & 0.54 \\
\hline & Overall & 3.91 & 0.18 \\
\hline
\end{tabular}


As can be seen in Table 2, the overall mean score of the eight items showing the non-English major students' motivation to learn English was at medium level $(\mathrm{M}=3.91, \mathrm{~S} . \mathrm{D}=.18)$.

Table-3. Statistics showing non-English major students 'motivation.

\begin{tabular}{l|l|c|c}
\hline No & Factors & Mean & Std. Deviation \\
\hline 1 & Teacher's personality & 3.92 & 0.58 \\
\hline 2 & Teacher's methodology & 3.89 & 0.56 \\
\hline 3 & Facilities for studying & 3.96 & 0.58 \\
\hline 4 & Classmates & 4.02 & 0.61 \\
\hline & Overall & 3.95 & 0.06 \\
\hline
\end{tabular}

Table 3 shows the average mean of four main factors and the overall mean score shows that students' motivation was rather high $(\mathrm{M}=3.95, \mathrm{SD}=.06)$, indicating that these students were quite enthusiastic about studying English in the classroom.

It is clear that all the factors are ranked at agreement level in the five-point Likert scale. It is clear that teacher characteristics contribute to motivate students in the classroom receiving $\mathrm{M}=3.92$. The component "teacher's methodology" is at agreement level $(\mathrm{M}=3.89)$. The factors related to "facilities for studying" and "classmates" also obtained agreement ranking from the respondents ( $M=3.96$ and $M=4.02$ respectively). The details of the four-factor analysis have been explored below.

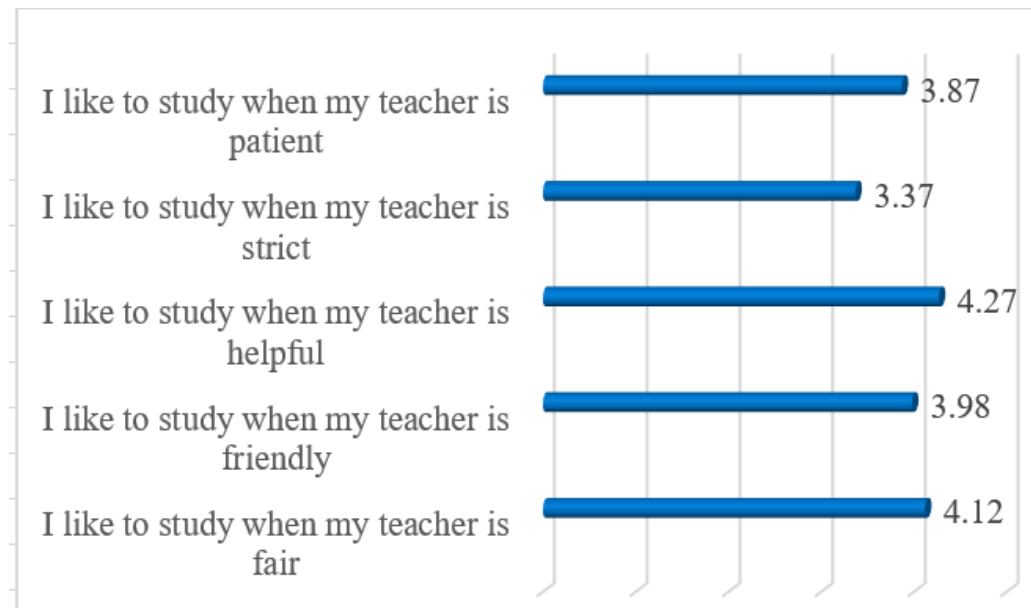

Figure-1. Teacher's personality

From Figure 1, it can be seen that four kinds of teacher's personality receiving more attraction from the participants. To be specific, they like studying with teacher who is helpful received the highest mean score $(\mathrm{M}=4.27)$ which falls into the highest level of the five-point scale. Three qualities such as "fairness, friendliness and patience" received the mean scores at the agreement level $(\mathrm{M}=4.12, \mathrm{M}=3.98$ and $\mathrm{M}=3.87$ respectively). By contrast, most of the students showed less concern on the factor "Teacher is strict." $(\mathrm{M}=3.37)$. It means that strict characteristic is the personality that is perceived as the factor demotivating the students.
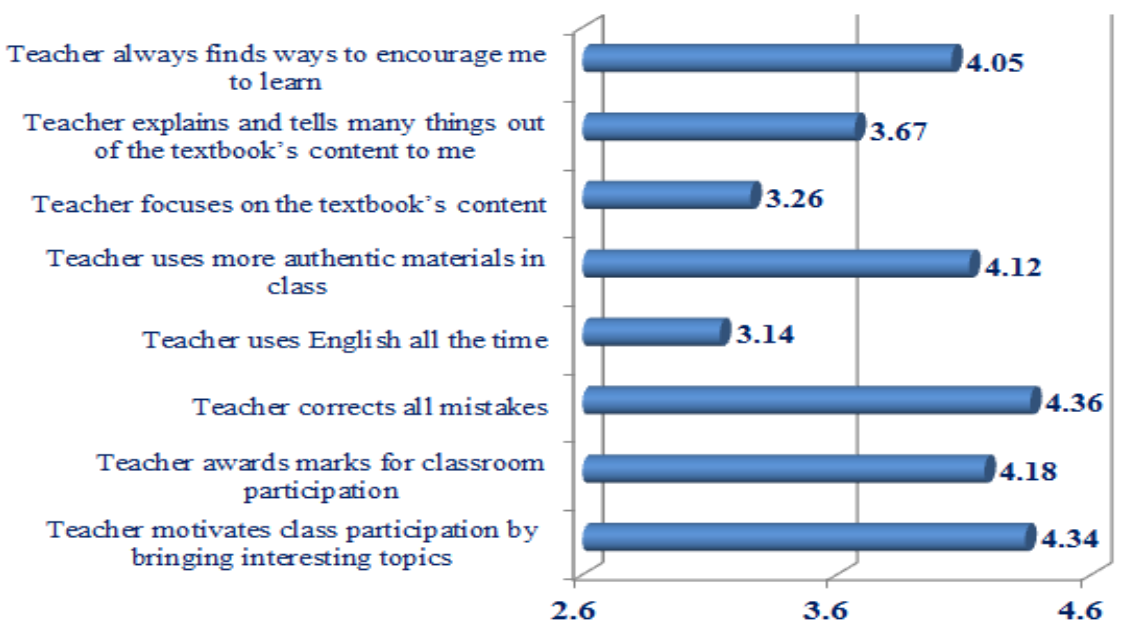

Figure-2. Teacher's methodology. 
The results presented in Figure 2 demonstrate that the teacher's methodology can influence the nonEnglish major students' motivation. Most of the techniques raised in the questionnaire received good feedback from the students. Among the items related to teacher's methodology, two items "correcting all mistakes" and "bringing interesting topics" received the highest mean scores $(M=4.36$ and $M=4.34$ respectively) which are at the highest level of the five-point Likert scale. Other items such as "teacher awards marks for classroom participation", "teacher uses authentic materials in class", "teacher awards marks for classroom participation", "teacher finds ways to encourage me to learn" are believed to promote their motivation and they have the mean scores of the agreement level in the five-point scale. On the other hand, the statements "use English all the time" and "teacher focuses on the textbook's content" received low ranking by the participants $(\mathrm{M}=3.14$ and $\mathrm{M}=3.26$ respectively). It can be explained that though the students are learning English they are demotivated if their teacher uses English frequently in class and only teaches them what is available in the textbook.

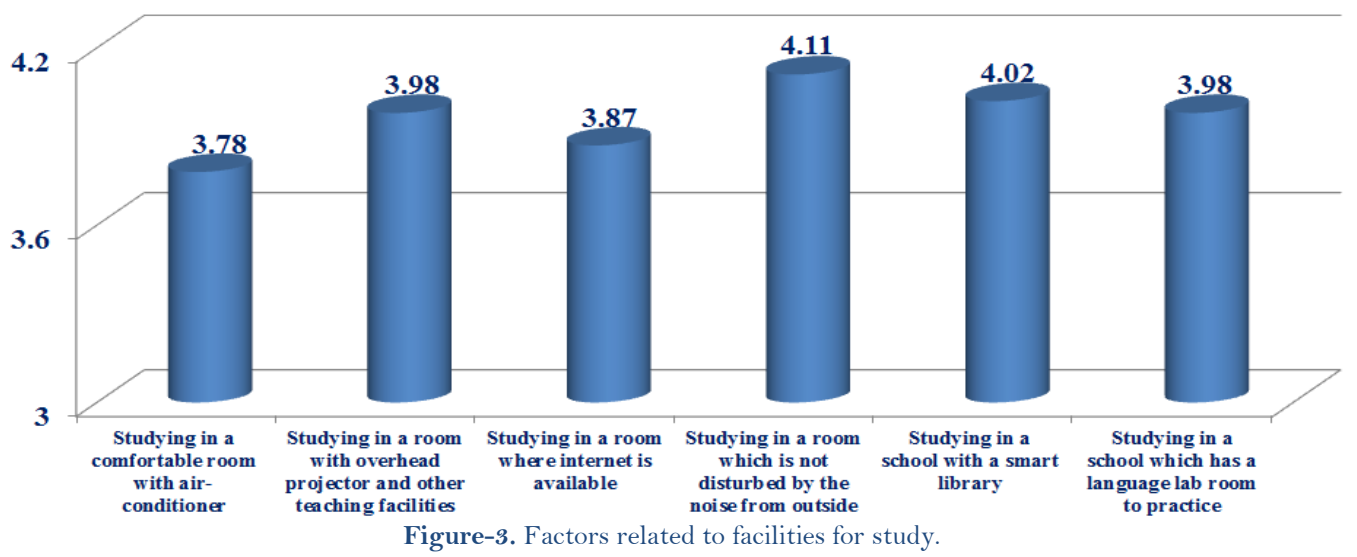

As can be observed from Figure 3, the factors related to facilities for learning are the components in this study which are supported by most of the respondents. All of the elements in this type of factors received an agreement from the respondents. The lowest mean scores which are related to the facilities equipped for the classroom such as "studying in a comfortable room with air-conditioner" $(\mathrm{M}=3.78)$, "studying in a room with overhead projector..." $(\mathrm{M}=3.98)$ or "studying in a room where the Internet is available" $(\mathrm{M}=3.87)$ are all in agreement level. The item which received the highest mean score is "studying in a room which is not disturbed by the noise from outside" $(M=4.11)$. It can be explained that the participants feel distracted from their lessons due to the outside noise.

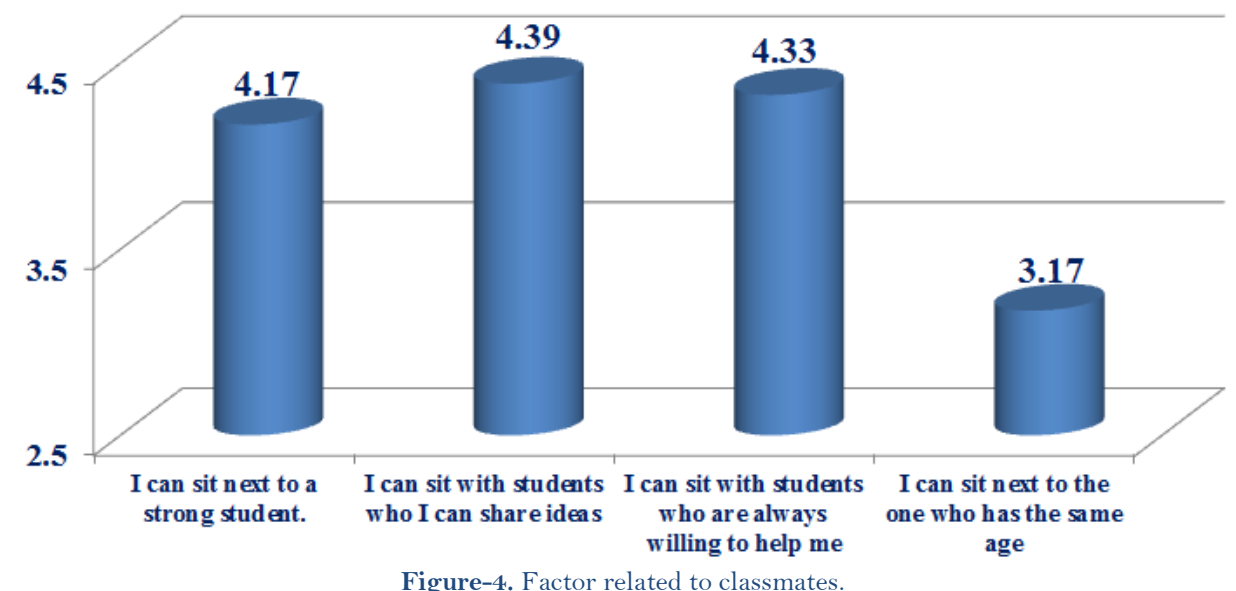

Figure 4 shows that three items "sitting next to a strong student, "sitting with students who can share ideas" and "sitting next to students who are always willing to help" received highest agreement from respondents $(\mathrm{M}=4.39, \mathrm{M}=4.33$ and $\mathrm{M}=4.17)$ respectively. It is apparent that students are unconcerned with the age of their friends $(\mathrm{M}=3.17)$.

\section{Discussion}

The data from the study could answer for the first research question. It means that the non-English majored students are motivated to learn English at university. As can be seen from the analysis of a five-point 
Likert scale, the overall mean score with $\mathrm{M}=3.95$ is at rather high level and shows that these students are motivated to learn English in their academic program.

The findings also illustrate that the four main factors can contribute to non-English major students in learning English. Firstly, the factor which obtained the highest rating in this study is related to "classmates". It can be explained that these learners seek much support from their friends in class. The results are supported by results of other studies such as Oroujlou and Vahedi (2011) and Khau and Thach (2021) who found that the learners feel more comfortable in the learning environment where they know all of their friends and could help each other. It can be explained that these students feel safe to express their ideas as well as share their ideas in their comfort zone. It can confirm the role of peers in the context of English as a foreign language. Secondly, it is found that the three other groups of factors related to "teacher's personality" and "teacher's methodology" received similar rating from the respondents which is at agreement level. One of the most crucial factors to enhance learners' interest and desire for learning is teachers or instructors. The results indicate that there is a link between motivation and the teacher's personality which are supported by the studies of Seda and Zahitjan (2016); Noemi (2014) and Khau and Thach (2021) who clarified that students are motivated when their teachers' personality is preferable. A good relationship between learners and teacher can support learner motivation. Nguyen (2015) also made clear that teachers' behavior and teachers' support to students will increase students' enthusiasm to study English. Besides, teachers are believed to mainly support students in classrooms so teacher's methodology somehow influences students' motivation. It is obvious that the students seek much help from teacher that is the reason many students wish to be corrected errors. The findings of Ochoa et al. (2016) concluded that communicative activities are inspiring and students are highly motivated by teachers' activities. The findings of the current study assert the findings of Al-Ta (2018) who assumed that students are highly motivated to learn English in both integrative and instrumental contexts. Finally, the factor related to "facilities for studying" also obtained the agreement rating of the respondents. The reason for this rating could possibly come from the classrooms with adequate equipment provided at their institution which is believed to promote their learning process. It is clear that language learners are highly influenced by the learning environment. This finding is aligned with what is found in the study of Le (2012) and Khau and Thach (2021) which concluded that poor learning conditions may demotivate students to learn English.

Overall, the four group factors of the current study almost reached the level of agreement in the five-point Likert scale. It is clear that these students' motivation is highly affected by classmates, teacher's personality, teacher's methodology and facilities for learning. These students seem to be aware of the role of peers, instructors and learning environment in a language classroom.

\section{Conclusion}

The findings could address the two research questions of the study. Overall, the participants of the present study are motivated to learn English at university though the level is found to be at medium level. Classmates are found to be the most important factor group which could enhance the non-English major students' motivation. Furthermore, the teacher's personality and teacher's methodology are found the important factors which contribute to the learners' motivation because teachers could inspire students to learn in the classroom. Besides, learning facilities are also found to be the factor boosting these students' motivation. To sum up, all the four groups of factors can affect leaners' motivation though the levels of perceptions are different in each factor group. The findings of the study could support the research on motivation. Based on what is found from the study, some implications could be drawn. To improve motivation in language, teachers should create a supportive learning environment in which students can help each other and teacher can be a facilitator or a supporter. Teachers should be careful in choosing or designing the activities which can encourage or motivate students to learn. In addition, teacher's personality and facilities for studying can contribute to improving motivation in class. Learners are found to learn better with teachers who are friendly, helpful and less demanding. Learners are also appreciated to learn with their best when they are well equipped with modern facilities.

The present study could only focus on a small sample of 54 non-English majors that the researcher could contact. We are sure that the results would be more persuasive if could be done with larger population and it could be better if more instruments would be implemented.

\section{References}

Al-Ta, M. H. (2018). Integrative and instrumental motivations for learning English as a university requirement among undergraduate students at Al-Jazeera University/Dubai. International Journal of Learning and Development, 8(4), 89-105. Available at: https://doi.org/10.5296/ijld.v8i4.13940.

Bernaus, M., \& Gardner, R. C. (2008). Teacher motivation strategies, student perceptions, student motivation, and English achievement. The Modern Language Journal, 92(3), 387-401.

Brown, H. D. (2000). Principles of language learning and teaching (Vol. 4). New York: Longman.

Dörnyei, Z. (1994). Motivation and motivating in the foreign language classroom. The Modern Language Journal, 78(3), 273-284. Available at: https://doi.org/10.1111/j.1540-4781.1994.tbo2042.x.

Ebata, M. (2008). Motivation factors in language learning. The Internet TESL Journal, 14(4).

Falk, J. (1978). Linguistics and language: A survey of basic concepts and implications (2nd ed.): John Wiley and Sons. 
Florentina, H., Cathy, D. E., \& Iqbal, A. A. (2020). Motivation and socio-cultural milieu of second language learners: Considerations involved in English teaching. Canadian Center of Science and Education, 13(5), 149-163. Available at: https://doi.org/10.5539/elt.v13n5p149.

Gardner, R. C. (1985). Social psychology and second language learning: The role of attitudes and motivation: Arnold.

Gilakjani, A. P., Leong, L. M., \& Sabouri, N. B. (2012). A study on the role of motivation in foreign language learning and teaching. International Journal of Modern Education E Computer Science, 4(7), 9-16.

Khau, A. H., \& Thach, L. P. (2021). Motivation in foreign language classrooms at tertiary level: A case study. Vietnam Journal of Education, 5(2), 32-40. Available at: https://doi.org/10.52296/vje.202 1.97.

Le, T. T. (2012). An empirical research into EFL learners' motivation. Theory and Practice in Language Studies, 2(3), 430439.

Nguyen, N. T. L. (2015). How to motivate non-English major students in Vietnamese universities of education to learn English. Paper presented at the 6th International Conference on TESOL: Responding to Challenges of Teaching English for Communication, Ho Chi Minh City.

Noemi, O. R. (2014). The influence of motivation in the foreign language learning process. COREA - aggregating the world's open access research papers. Retrieved from https://core.ac.uk/download/pdf/92992568.pdf.

Ochoa, C., Cabrera, P., Quiñónez, A., Castillo, L., \& González, P. (2016). The effect of communicative activities on efl learners' motivation: A case of students in the amazon region of ecuador. Colombian Applied Linguistics Journal, 18(2), 39-48. Available at: https://doi.org/10.14483/calj.v18n2.10018.

Oroujlou, N., \& Vahedi, M. (2011). Motivation, attitude, and language learning. Procedia-Social and Behavioral Sciences, 29, 994-1000. Available at: https://doi.org/10.1016/j.sbspro.2011.11.333.

Seda, E., \& Zahitjan, K. (2016). The factors affecting learners' motivation in English language education. Journal of Foreign Language Education and Technology, 1(1), 18-38.

Shahla, K. S., \& Takkac, M. (2021). Motivational factors for learning English as a second language acquisition in Canada. Higher Education Studies, 11 (1), 160-170. Available at: https://doi.org/10.5539/hes.v $11 \mathrm{n} 1 \mathrm{p} 160$.

Tsai, C.-C., \& Chang, I.-C. (2013). The study on motivation and anxiety of English learning of students at a Taiwan Technical University. International Journal of English Language Teaching, 1(1), 24-41. 